\title{
Does biotope diversity promote an increase of genetic variation in the bank vole population?
}

\author{
Marek GĘBCZYŃSKI and Mirosław RATKIEWICZ
}

Gẹbczyński M. and Ratkiewicz M. 1998. Does biotope diversity promote an increase of genetic variation in the bank vole population? Acta Theriologica 43: 163-173.

An electrophoretic study of the variation at 40 protein loci in the bank vole Clethrionomys glareolus (Schreber, 1780) was performed in spring 1994-1996 and in autumn 1994 and 1995. A total of 153 individuals from deciduous forest and 122 from coniferous forest subpopulations were collected. During the whole time of the study in spring the coefficient of trappability was $4.1 \%$ in deciduous forest and $3.0 \%$ in coniferous forest; in autumn $9.3 \%$ and $7.6 \%$, respectively. In spring there were no significant differences in allele frequencies between the subpopulations studied. The samples from deciduous and coniferous forests were genetically similar. However, in autumn these differences were statistically significant. Although the level of heterozygosity in both, neighbouring subpopulations is similar, its changes in consecutive seasons have different values. From the calculations performed, based on the level of genetic differentiation between subpopulations $\left(F_{s t}\right)$, it can be concluded that the level of gene flow between the voles from two biotopes in spring is greater than in autumn. We hypothesise that the essence of this phenomenon lies in a non-random fraction of migrants between the biotopes studied. The data presented in the study indicate that the genetic structure in two neighbouring subpopulations of the bank vole undergoes different processes.

Institute of Biology, University of Białystok, Świerkowa 20 B, 15-950 Białystok, Poland

Key words: Clethrionomys glareolus, isozyme electrophoresis, genetic variation, populations, biotope diversity

\section{Introduction}

In animals, both the increase and decrease of natural population ranges are associated with formation of local populations (called subpopulations or demes). Such subpopulations differ in their time of persistence. In rodents, with the bank vole Clethrionomys glareolus (Schreber, 1780) as a good example - because of its well known ecology, the process of rising and declining of populations continues in two different time rhythms. The first is annual, associated with seasonal breeding persisting intensively in spring and early summer, but practically nonexistent in other seasons of the year. On average, this results in a four-fold increase of vole numbers at the beginning of autumn in comparison with the end of winter Pucek et al. 1993). The other rhythm of population size changes is of multiannual character. An increase takes place after a period of moderate population numbers and lasts 4 to 7 years. The population size, calculated as a 
mean for the whole year, may differ in consecutive years as much as 17 times. Also, the number of voles in autumn may be even 61 times higher in comparison with autumn in years of low population size (Pucek et al. 1993). The fluctuations of population size not only cause the increase of vole population density in biotopes of permanent presence (so-called optimal), but they also cause an increase of local ranges in suboptimal biotopes (Gliwicz 1991). New subpopulations are formed in areas which were not settled at all by voles in years of low vole numbers, or the population density in such parts of species range was lower than in optimal biotopes. This raises a question whether the voles which disperse and increase the number of individuals in poorely inhabited areas or even colonise the new places are a random fraction from the mother population, or the migrants are the individuals with the characters differing from the average. This has a great influence on the genetic structure of the newly arising subpopulations. It is also said (Patton and Smith 1990, Whitlock 1992) that genetic characters of the groups of individuals considerably depend on spatial localisation of populations in relation to each other. Geographically close populations are genetically more similar than populations isolated by a large distance. This does not determine the character of genetic changes caused by fluctuations in population number resulting from both spatial ("dense" versus "diluted" populations) and seasonal changes in the population size. The existence of fluctuations in the number of individuals in two neighbouring subpopulations can be considered a particularly convenient experiment. There are no available data concerning such situations. There is either no theoretical agreement whether colonisation, disappearing and recolonisation processes increase (Wright 1977) or, conversely, decrease (Slatkin 1987) genetic differences among populations. These opposite opinions are softened by other theoretical considerations on this subject. For example, Wade and McCauley (1988) try to clarify Wright's and Slatkin's opinions showing that increased gene flow between adjacent populations may decrease genetic differences only in particular cases. However, in general gene flow increases genetic differentiation between subpopulations. Moreover, Whitlock and McCauley (1990) emphasised that the mode of colonisation is a significant factor, which establishes genetic differences and similarities between the subpopulations, as the colonisation may be (a) random or (b) selective inflow of individuals. However, there are only few empirical data concerning genetic properties of subpopulations. One study showed only the existence of certain differences in particular populations, without considering dynamics of the process in invertebrates (McCauley and Eanes 1987, Rank 1992). Thus the purpose of this study was to analyse data about genetic structure of the neighbouring bank vole subpopulations in different seasons and consecutive years.

We assumed that this would allow us to: (a) Estimate the dynamics of genetic processes influencing the structure of population in spring and autumn. (b) Determine whether the resident population in deciduous forest (optimal biotope) differs from the subpopulation inhabiting coniferous forest (suboptimal biotope) undergoing a higher fluctuation in number. (c) Answer the possible question whether, 
during a dramatic change in vole numbers, the genetic structure of the population changes considerably.

\section{Material and methods}

A total of 294 bank voles Clethrionomys glareolus were live-trapped in the Solnicki Forest, near Białystok (NE Poland) in three consecutive years (1994-1996) during spring and autumn (Table 1). The trapping sites were located in two neighbouring biotopes: deciduous and mixed coniferous forest. After killing animals, blood, liver, salivary gland and kidney tissue were taken for electrophoresis. Then, vole sex was determined and eye lens were taken to estimate the age of the individuals. When a total dry mass of eye lens was equal to or higher than $6 \mathrm{mg}$ in bank voles trapped in spring they were considered overwintered individuals (Kozakiewicz 1976). Blood was centrifuged at $12000 \mathrm{rpm}$ for 3 minutes to separate serum and blood cells; other tissues were homogenised in $0.01 \mathrm{M}$ phosphate buffer ( $\mathrm{pH}=7.5$ ) and centrifuged at $12000 \mathrm{rpm}$ for 20 minutes. A total of 40 protein loci were studied in each specimen: alcohol dehydrogenase $(A d h), \alpha$ and $\beta$ glycerol-3 phosphate dehydrogenase ( $\alpha G p d-1$, $\beta G p d-1, \beta G p d-2)$, sorbitol dehydrogenase $(S d h)$, lactate dehydrogenase $(L d h-1, L d h-2)$, malate dehydrogenase (Mdh-1 Mdh-2), malic enzyme (Me-1), isocitrate dehydrogenase (Idh-1, Idh-2), 6-phosphogluconate dehydrogenase $(P g d)$, xanthine dehydrogenase $(X d h)$, NADH-diaforase $(D i a)$, catalase (Cat), superoxide dismutase (Sod-1, Sod-2, Sod-3), aspartat-aminotransferase (Aat-1, Aat-2), phosphoglucomutase (Pgm-1, Pgm-2, Pgm-3), esterase (Est-B3, Es-D), $\alpha$-amylase (Amy-1, Amy-2, Amy-3, Amy-4), peptidase (Pep-1, Pep-2), aminoacylase (Acy), aldolase (Ald-1, Ald-2), aconitase (Acon-1, Acon-2), glucose phosphate isomerase ( $G p i)$, albumin (Alb), and protein-1 (Prot-1).

For the most of enzymes horizontal starch gel electrophoresis was performed according to Selander et al. (1971), Harris and Hopkinson (1976) and Quavi and Kit (1980). Only for aconitase-1, -2 , phosphoglucomutase-1, $-2,-3$ and diaphorase cellulose acetate plates (Helena Labs. Texas) were used witı staining methods described by Searle (1985). A locus was considered polymorphic if more than one allele was detected. The alleles at polymorphic loci were designated alphabetically with increasirg anodal migration of the corresponding allozymes.

For the genetic data analysis a computer program, Biosys-1, of Swofford and Selander (1989) was used. The differences in allele frequencies between samples were tested using $\chi^{2}$-test for homogeneity. Deviations from Hardy-Weinberg equilibrium in subpopulations were tested using $\chi^{2}$ goodness-of-fit test. The value of observed average heterozygosity in each studied group were not normally distributed (tested by $\chi^{2}$-test at $p=0.05$ ). Therefore, Kruskal-Wallis one-way analysis by ranks test (Zar 1984) was performed to test the differences in observed average heterozygosity among populations. To estimate the theoretical number of migrants $\left(N_{m}\right)$ entering a given population the equation $N_{m}=$ $\left[\left(1 / F_{s t}\right)-1 / 4\right]$ was employed (Wright 1978$) . F_{s t}$ was estimated as a mean across polymorphic loci.

\section{Results}

The sharacteristics of deciduous and coniferous subpopulations of the bank vole

Thedata concerning captures of bank voles (Table 1) show that there is clearly visible seasonal variation in trappability. The coefficient of trappability in spring ranges from 1.7 to $4.7 \%$. In autumn it ranges from 5.5 to $10.4 \%$. It can be also said that in general the bank vole subpopulation from coniferous forest is characierised by lower trappability in comparison with the subpopulation from a decidurus forest. Despite this the trappability value was nearly equal in both subpopulations in autumn 1995, while in autumn 1994 and spring 1996 it was 
Table 1. The number of collected bank voles $(n)$ in three consecutive years 1994-1996 in spring and autumn, in two neighbouring populations: from deciduous and coniferous forests. $\mathrm{M}$ - males, $\mathrm{F}$ - females, $T I$ - trappability coefficient.

\begin{tabular}{lllcccc}
\hline Forest type & \multicolumn{1}{c}{ Season and year } & $n$ & M & F & $T I$ \\
\hline Deciduous & Spring & 1994 & 31 & 18 & 13 & 4.6 \\
& Autumn & 1994 & 29 & 9 & 20 & 10.4 \\
& Spring & 1995 & 29 & 23 & 6 & 4.7 \\
& Autumn & 1995 & 31 & 10 & 21 & 8.3 \\
Coniferous & Spring & 1996 & 33 & 19 & 14 & 3.5 \\
& Spring & 1994 & 28 & 16 & 12 & 3.5 \\
& Autumn & 1994 & 25 & 10 & 15 & 5.5 \\
& Spring & 1995 & 11 & 6 & 5 & 3.0 \\
& Autumn & 1995 & 46 & 23 & 23 & 8.8 \\
& Spring & 1996 & 12 & 7 & 5 & 1.7 \\
\hline
\end{tabular}

twice as big as in coniferous forest. On the other hand, during three consecutive years of study the coefficient of trappability in spring was from 1.3 to 2 times lower in coniferous forest than in deciduous forest. The variation of trappability coefficient value allows us to assume that the density of voles in the coniferous forest was more variable than in the deciduous forest, especially in autumn. It can also be concluded that in four out of five seasons during which the study was conducted the number of bank voles in the deciduous forest subpopulation was higher than in the coniferous forest. These differences are more evident in spring during three years of study. From the analysis of trappability coefficient value in autumn 1994 it can be concluded that the number of voles in the deciduous forest subpopulation was twice as high as in the coniferous forest subpopulation.

\section{Differences in allele frequencies between the bank vole subpopulations}

The following 28 loci were found to be monomorphic with the same allele in all the individuals studied: Aat-1, Acon-1, Acon-2, Adh, Alb, Ald-1, Ald-2, Amy-1, Amy-4, Cat, $\alpha G p d-1, \beta G p d-1, \beta G p d-2, G p i, I d h-1, I d h-2, L d h-1, M e-1, M d h-1$, Mdh-2, Pep-1, Pgm-1, Prot-1, Sod-1, Sod-2, Sod-3, Sdh and Xdh. The other 12 loci were polymorphic with more than one allele in at least one individual: Aat-2, Acy-1, Amy-2, Amy-3, Dia, Es-D, Es-B3, Ldh-2, Pep-2, Pgd, Pgm-2 and Pgm-3. Allele frequencies for the polymorpic loci are given in the Appendix.

The comparison of allele frequencies in deciduous and coniferous forest subpopulations shows that the frequencies change seasonally (Table 2 and Appendix). In spring, during three years of the study no significant differences in allele frequencies between the deciduous and coniferous forest subpopulations were found. On the other hand, in autumn the opposite situation was observed. Both, in 1994 and 1995 the differences in allele frequencies between the bank vole sub- 
populations are statistically significant (Table 2). It can be concluded that in spring, after a severe winter reduction in the number of voles (compare also $T I$ in Table 1), selection pressure makes the studied populations genetically similar. No significant deviations from Hardy-Weinberg proportions were found except Sal-2 locus $(p=0.012)$ in deciduous forest subpopulation in spring 1996 and Acy locus $(p=0.006)$ in autumn 1994.
Table 2. $\chi^{2}$-test for homogeneity in allele frequencies at polymorphic loci between bank voles inhabiting deciduous and coniferous biotopes. ${ }^{\mathrm{a}}$ significant difference $(p=0.044)$ only for peptidase-2 locus.

\begin{tabular}{lll}
\hline \multicolumn{2}{l}{ Season and year } & \multicolumn{1}{c}{$p$} \\
\hline Spring & 1994 & 0.84 \\
Spring & 1995 & 0.081 \\
Spring & 1996 & $0.23^{\mathrm{a}}$ \\
Autumn & 1994 & 0.00002 \\
Autumn & 1995 & 0.0003 \\
\hline
\end{tabular}

\section{The level of heterozygosity in deciduous and coniferous forest populations} of the bank vole

The winter mortality in the bank voles studied changes their composition within the population (Table 3 ). It results in a different level of heterozygosity in spring compared with autumn. Observed average heterozygosity $\left(H_{0}\right)$ differs among populations $(H=37.72, p<0001)$. The level of $H_{o}$ changes differently in both subpopulations (Table 3 ). The data presented in Table 3 show that average heterozygosity in both subpopulations is similar in autumn, as the observed heterozygosity $\left(H_{o}\right)$ ranges from 6.3 to $6.5 \%$. If only the polymorphic loci are included (12 out of 40 studied), the average heterozygosity also varies slightly (from 21.5 to $23 \%$ ). This shows that in autumn both subpopulations become similar in respect to this coefficient $\left(H_{0}\right)$. However, in spring the picture is more

Table 3. The level of average heterozygosity (in per cent) in the bank voles from the coniferous and deciduous forest subpopulations, in consecutive seasons and years. $n$ - number of individuals studied. $H_{0}$ - observed average heterozygosity, $H_{\mathrm{e}}$ - expected average heterozygosity.

\begin{tabular}{|c|c|c|c|c|c|c|}
\hline \multirow{2}{*}{ Forest type } & \multirow{2}{*}{\multicolumn{2}{|c|}{ Season and year }} & \multirow{2}{*}{$n$} & \multicolumn{2}{|c|}{ All loci } & \multirow{2}{*}{$\frac{\text { Polymorphic loci }}{H_{0}}$} \\
\hline & & & & $H_{0}$ & $H_{\mathrm{e}}$ & \\
\hline \multirow[t]{5}{*}{ Deciduous } & Spring & 1994 & 20 & 4.3 & 5.4 & 15.8 \\
\hline & Autumn & 1994 & 30 & 6.3 & 6.2 & 23.0 \\
\hline & Spring & 1995 & 25 & 5.9 & 6.3 & 21.4 \\
\hline & Autumn & 1995 & 30 & 6.5 & 6.7 & 23.5 \\
\hline & Spring & 1996 & 32 & 7.3 & 7.5 & 26.6 \\
\hline \multirow[t]{5}{*}{ Coniferous } & Spring & 1994 & 27 & 5.0 & 5.5 & 17.6 \\
\hline & Autumn & 1994 & 26 & 6.2 & 6.1 & 21.5 \\
\hline & Spring & 1995 & 7 & 8.9 & 7.9 & 32.5 \\
\hline & Autumn & 1995 & 46 & 6.3 & 6.4 & 22.8 \\
\hline & Spring & 1996 & 12 & 6.1 & 6.8 & 22.1 \\
\hline
\end{tabular}


complicated. During two years (1994 and 1995) $H_{0}$ value was higher in the coniferous forest vole subpopulation than in the deciduous forest subpopulation. However, in spring 1996 this tendency was reversed. The value of $H_{0}$ ranged from 4.3 to $8.9 \%$. If only the polymorphic loci are included the variation in $H_{0}$ ranges from 15.8 to $32.5 \%$. Thus, the observed heterozygosity in both subpopulations differs more in spring than in autumn and it also undergoes greater springtime fluctuation than in autumn.

\section{Discussion}

It has been found that in spring the average heterozygosity of bank voles inhabiting deciduous biotopes in Białowieża Primeval Forest is $4.2 \%$ and it is higher than in autumn as it becomes $3.2 \%$ in residents and $3.5 \%$ in migrants (Fedyk and Gębczyński 1980). These seasonal changes are explained by the authors by the better survival of heterozygous individuals during the winter. Although we found changes of average heterozygosity in two bank vole subpopulations from Solnicki Forest in the consecutive seasons, they cannot be undoubtedly assigned to higher mortality of homozygous individuals in winter. In some cases the average heterozygosity was lower in spring than in the previous autumn (deciduous forest: autumn 1994 - spring 1995), and remained unchanged (coniferous forest: autumn 1995 - spring 1996). In other cases (deciduous forest: autumn 1995 - spring 1996, coniferous forest: autumn 1994 - spring 1995) a similar process of seasonal changes of $H_{O}$ value in the bank vole populations took place (Fedyk and Gębczyński 1980). We believe that the explanation is not due to weather conditions since in the case of the subpopulations observed, after the same winter $(1994 / 95)$ this value $\left(H_{0}\right)$ in the deciduous forest was reduced, while in coniferous forest subpopulation it clearly increased, in comparison with autumn 1994. After the next winter (1995/96) in the deciduous forest subpopulation the average heterozygosity $H_{0}$ was greater in spring while it did not change in the coniferous forest subpopulation. These changes in $H_{0}$ value are not associated with the amount of winter reduction of voles, or our trappability coefficient results. The strong reduction in number of individuals in the population during winter does not always result in the increase of the $H_{o}$ value. Therefore, the earlier hypothesis of Smith et al. (1978) suggesting differential winter mortality of homozygous and heterozygous individuals of rodents, and confirmed in the bank vole populations from deciduous biotopes of Białowieża Primeval Forest (Fedyk and Gębczyński 1980) was only partly supported here. Despite the need of the further attempts to answer the question whether a winter season is characterised by unequal survival of homozygous and heterozygous rodents, the geographical differences in genetic structure of the bank vole populations should be taken to a consideration. It has been shown that the bank vole population on Jutland Pennisula consists almost only of homozygotes, where $H_{o}=0.6 \%$ (Gębczyński et al. 1986). In 10 
populations in Austria $H_{O}$ ranges from 2.8 to $8.5 \%$ (Leitner and Hartl 1988) and in 5 populations in southern and eastern Poland this value ranges from 3.9 to 6.3\% (Gębczyński et al. 1993).

An explanation is needed for the fact that in the present study no significant differences in allele frequencies between two subpopulations were found in spring, while in autumn these differences were highly statistically significant. This surprising fact may be explained in three different ways. First, it may be due to small sample sizes in spring 1995 and 1996. The second possible hypothesis assumes that migration in autumn does not exist or only takes place within each biotope. This allows an independent genetic differentiation within the studied subpopulations. Thus the changes in genetic structure during a peak of bank vole number are different even in neighbouring subpopulations. The other hypothesis relies on the assumption that migration in autumn takes place and allows the exchange of the individuals between the subpopulations. However, the migrants do not represent a random sample from a population. This fraction of the individuals in the subpopulations, which shows a tendency to disperse, belongs to a different genetic category than those which remain close to their place of birth. It seems - according to the previous data concerning ecology of the bank vole (Petrusewicz 1983, Gliwicz 1991) - that the third hypothesis is more probable. The calculation of the number of migrants $\left(N_{m}\right)$ between two subpopulations (Wright 1978) seems also to confirm the third hypothesis. Slatkin and Barton (1989) showed that, under the assumption that individuals migrate at random and mutation rate is negligible, $N_{m}$ calculated using $F_{s t}$ is a quite reliable estimate of gene flow between populations which are at Hardy-Weinberg equilibrium. In the case of our study the level of gene flow found between deciduous and coniferous forests subpopulations is different (Table 4). The data presented in Table 4 show the theoretical number of individuals exchanged between the subpopulations in different seasons under study, which would result in the observed genetic differentiation between subpopulations. It can be assumed from these calculations that exchange of the individuals between the subpopulations seems to be lower in autumn than in spring. However, $N_{m}$ changes considerably in consecutive years.

Table 4. The genetic differentiation $F_{s t}$ and the level of gene flow as the number of migrants $\left(N_{m}\right)$ between the bank vole subpopulations from deciduous and coniferous forests in the different seasons in years 1994-1996.

\begin{tabular}{lccr}
\hline \multicolumn{2}{l}{ Season and year } & $F_{\text {st }}$ & $N_{m}$ \\
\hline Spring & 1994 & 0.007 & 35 \\
Spring & 1995 & 0.029 & 8 \\
Spring & 1996 & 0.019 & 13 \\
Autumn & 1994 & 0.046 & 5 \\
Autumn & 1995 & 0.019 & 13 \\
\hline
\end{tabular}


It should also be mentioned here that genetic differentiation between subpopulations $\left(F_{s t}\right)$ found in our study is relatively small, as it is always lower than 0.05 (Wright 1978). If we assume that average $N_{m}$ in spring during three consecutive years of the study and in autumn 1994 and 1995 is genuine, despite considerable variation, it could be concluded that gene flow was greater in spring than in autumn. Such a conclusion is inconsistent with our understanding of bank vole ecology. The bank vole is characterised by moderate ability to migrate. Migration may occur during any time of the year, but it is most intense in autumn every year when number of voles is the greatest (Petrusewicz 1983). Males migrate more often than females, younger individuals than older ones (Wolton and Flowerdew 1985, Gliwicz 1991). Thus, the phenomenon could be explained by the hypothesis of a non-random fraction of migrants between deciduous and coniferous forests in autumn. The main direction of migration remains an open question. Recently Kierus (1996) postulated (contrary to former assumptions) that voles may migrate from coniferous to deciduous forests. The additional argument showing different processes forming the genetic structure in two vole populations is, we suspect, the genetic differentiation $\left(F_{s t}\right)$ coefficient and $N_{m}$ values calculated for the consecutive bank vole generations (Table 5). $F_{s t}$ and $N_{m}$ between generations are, on average similar in the two subpopulations studied. However, in the coniferous forest subpopulation these values are nearly the same in four out of five generations. $N_{m}$ ranges from 10 to 12 individuals, and only in spring $N_{m}$ was 25 . On the other hand the value of this coefficient ranges from 7 to 62 (Table 5). It may indicate a great, probably selective migration, affecting the subpopulation from deciduous forest. This could eventually support an assumption of migrating individuals from coniferous to deciduous forest.

Data presented here allow us to conclude that: (a) changes of genetic structure in the bank vole populations are different in spring and autumn, (b) the subpopulation inhabiting an optimal biotope for a given species is under different selection pressures compared with that from a sub-optimal biotope. In our opinion this conclusion is an important empirical corroboration of the suggestions proposed by

Table 5. The genetic differentiation $\left(F_{s t}\right)$ and the level of gene flow as the number of migrants $\left(N_{m}\right)$ between consecutive generations in bank vole subpopulations inhabiting deciduous and coniferoud forests. ad - overwintered voles, juv - voles born in a given year.

\begin{tabular}{llllll}
\hline \multirow{2}{*}{ Generation and season } & \multicolumn{2}{c}{ Deciduous forest } & & \multicolumn{2}{c}{ Coniferous forest } \\
\cline { 2 - 3 } \cline { 5 - 6 } & $F_{s t}$ & $N_{m}$ & & $F_{s t}$ & $N_{m}$ \\
\hline Spring 1994 ad - spring 1994 juv & 0.009 & 28 & & 0.010 & 25 \\
Spring 1994 juv - autumn 1994 juv & 0.004 & 62 & & 0.025 & 10 \\
Autumn 1995 juv - spring 1995 ad & 0.017 & 14 & & 0.021 & 12 \\
Spring 1995 ad - autumn 1995 juv & 0.036 & 7 & & 0.023 & 11 \\
Autumn 1995 juv - spring 1996 ad & 0.024 & 10 & & 0.024 & 10 \\
\hline
\end{tabular}


the theoreticians, suggesting that widely distributed species, inhabiting different biotopes, should be characterised by high genetic differentiation (Wright 1977, Lande 1988).

During the time of our study no data were collected concerning genetic processes in the bank vole population experiencing dramatic changes in number. The answer to this question demands further studies.

Acknowledgements: The study was supported by grant KBN no. 6P204 03206 . Technical assistance of J. Łobodzińska and P. Rode is acknowledged. We also thank A. Borkowska for help in statistical analyses. G. L. Dryden kindly checked the English. Critical comments by three anonymous reviewers helped us to improve the paper.

\section{References}

Fedyk A. and Gębczyński M. 1980. Genetic changes in seasonal generations of the bank vole. Acta Theriologica 25: 475-485.

Gębczyński M., Nielsen J. T. and Simonsen V. 1986. An electrophoric comparison between three sympatric species of rodents from Jutland, Denmark. Hereditas 104: 55-59.

Gębczyński M., Ratkiewicz M. and Dryden G. L. 1993. Electrophoretic variation among the five Polish populations of the bank vole. Biochemical Systematics and Ecology 21: 825-831.

Gliwicz J. 1991. Patterns of dispersal in non-cyclic populations of small rodents. [In: Animal dispersal. Small mammmals as a model. N. C. Stenseth and W. Z. Lidicker, Jr, eds]. Chapman and Hall: 147-159.

Harris H. and Hopkinson D. A. 1976. Handbook of enzyme electrophoresis in human genetics. North-Holland, Oxford: 1-172.

Kierus M. 1996. [The bank vole population dynamics in the two neighbouring forests: deciduous and mixed coniferous]. M Sc thesis, Institute of Biology, Warsaw University, Branch of Białymstok, Białystok: 1-37. [In Polish]

Kozakiewicz M. 1976. The weight of eye lens as the proposed age indicator in the bank vole. Acta Theriologica 21: $314-316$.

Lande R. 1988. Genetics and demography in biological conservation. Science 241: 1455-1460.

Leitner M. and Hartl G. 1988. Genetic variation in the bank vole Clethrionomys glareolus: biochemical differentiation among populations over short geographical distances. Acta Theriologica 33: 231-245.

McCauley D. E. and Eanes W. F. 1987. Hierarchical population structure analysis of the milkweed beetle, Tetraopes tertraophtalmus (Forster). Heredity 58: 193-201.

Patton J. L. and Smith M. F. 1990. The evolutionary dynamics of the pocket gopher Thomomys bottae with emphasis on California populations. University of California, Publication in Zoology 123: $1-161$.

Petrusewicz K. 1983. Patterns of population dynamics. [In: Ecology of the bank vole. K. Petrusewicz, ed]. Acta Theriologica 28, Suppl. 1: 145-148.

Pucek Z., Jędrzejewski W., Jędrzejewska B. and Pucek M. 1993. Rodent population dynamics in a primeval deciduous forest (Białowieża National Park) in relation to weather, seed crop, and predation. Acta Theriologica 38: 199-232.

Quavi H. and Kit S. 1980. Electrophoretic patterns of aminoacylase-1 (Acy-1). Biochemical Genetics 18: $669-679$.

Rank N. E. 1992. A hierarchical analysis of genetic differentiation in a montane leaf beetle, Chrysomela aeneicollis (Coleoptera, Chrysomelidae). Evolution 46: 1097-1111.

Searle J. B. 1985. Isoenzyme variation in the common shrew (Sorex araneus) in Britain, in relation to karyoptype. Heredity 55: 175-180. 
Selander R. K., Smith M. H., Yang S. Y., Johnson W. E. and Gentry G. B. 1971. Biochemical polymorphism and systematics of the genus Peromyscus. I. Variation in the old-field mouse (Peromyscus polionotus). Studies in Genetics VI, University of Texas Publications 7103: 49-90.

Slatkin M. 1987. Gene flow and the geographic structure of the natural populations. Science 236: $787-792$

Slatkin M. and Barton N. 1989. A comparison of three indirect methods for estimating average levels of gene flow. Evolution 43: 1349-1368.

Smith M. H., Manlove M. N. and Joule J. 1978. Spatial and temporal dynamics of the genetic organization of small mammal populations. [In: Small mammal population dynamics. D. Snyder, ed]. Special Publication Series of Pymatuning Laboratory of Ecology 5: 99-113.

Swofford D. L. and Selander R. B. 1989. Biosys-1: A computer program for the analysis of allelic variation in population genetics and biochemical systematics. Illinois Natural History Survey, Champaign: $1-50$.

Wade M. J. and McCauley D. E. 1988. Extinction and recolonization: their effects on the genetic differentiation of local populations. Evolution 42: 995-1005.

Whitlock M. C. 1992. Temporal fluctuations in demographic parameters and the genetic variance among populations. Evolution 46: 608-615.

Whitlock M. C. and McCauley D. E. 1990. Some population genetic consequences of colony formation and extinction: Genetic correlations within founding groups. Evolution 44: 1717-1724.

Wolton R. J. and Flowerdew J. R. 1985. Spatial distribution and movements of wood mice, yellow-necked mice and bank voles. Symposia of Zoological Socjety of London 55: 249-275.

Wright S. 1977. Evolution and the genetics of populations. 3. Experimental results and evolutionary deductions. University of Chicago Press, Chicago: 1-611.

Wright S. 1978. Evolution and the genetics of populations. 4. Variability within and among natural populations. University of Chicago Press, Chicago: 1-580.

Zar J. H. 1984. Biostatistical analysis. Prentice-Hall, Inc. Englewood Cliffs, New York: 1-718.

Received 14 April 1997, accepted 4 September 1997. 
Appendix. Allele frequencies in the bank vole subpopulations during 1994-1996 in Solnicki Forest. sp - spring, au - autumn, ad - overwintered voles, juv - voles born in a given year, dec - deciduous forest, con - coniferous forest, $n$ - number of individuals.

\begin{tabular}{|c|c|c|c|c|c|c|c|c|c|c|c|c|}
\hline Locus & $\begin{array}{c}\text { sp'94 } \\
\text { ad } \\
\text { dec }\end{array}$ & $\begin{array}{l}\text { sp'94 } \\
\text { ad } \\
\text { con }\end{array}$ & $\begin{array}{l}\text { sp'94 } \\
\text { juv } \\
\text { dec }\end{array}$ & $\begin{array}{l}\text { sp'94 } \\
\text { juv } \\
\text { con }\end{array}$ & $\begin{array}{c}\text { au'94 } \\
\text { juv } \\
\text { dec }\end{array}$ & $\begin{array}{c}\text { au'94 } \\
\text { juv } \\
\text { con }\end{array}$ & $\begin{array}{l}\text { sp’95 } \\
\text { ad } \\
\text { dec }\end{array}$ & $\begin{array}{l}\text { sp'95 } \\
\text { ad } \\
\text { con }\end{array}$ & $\begin{array}{c}\text { au'95 } \\
\text { juv } \\
\text { dec }\end{array}$ & $\begin{array}{c}\text { au'95 } \\
\text { juv } \\
\text { con }\end{array}$ & $\begin{array}{l}\text { sp'95 } \\
\text { ad } \\
\text { dec }\end{array}$ & $\begin{array}{l}\text { sp'96 } \\
\text { ad } \\
\text { con }\end{array}$ \\
\hline$L d h-2$ & $n=19$ & 28 & 11 & 6 & 30 & 26 & 25 & 7 & 30 & 46 & 32 & 12 \\
\hline$a$ & 1.00 & 1.00 & 1.00 & 1.00 & 0.98 & 0.94 & 0.98 & 0.86 & 1.00 & 0.92 & 0.98 & 0.96 \\
\hline$b$ & 0.00 & 0.00 & 0.00 & 0.00 & 0.02 & 0.06 & 0.02 & 0.14 & 0.00 & 0.08 & 0.02 & 0.04 \\
\hline$P g d$ & $n=19$ & 28 & 11 & 6 & 30 & 26 & 25 & 7 & 30 & 46 & 32 & 12 \\
\hline$a$ & 1.00 & 0.98 & 1.00 & 1.00 & 1.00 & 1.00 & 1.00 & 0.93 & 0.92 & 0.99 & 1.00 & 1.00 \\
\hline$b$ & 0.00 & 0.02 & 0.00 & 0.00 & 0.00 & 0.00 & 0.00 & 0.07 & 0.08 & 0.01 & 0.00 & 0.00 \\
\hline Aat -2 & $n=20$ & 28 & 11 & 6 & 30 & 26 & 25 & 6 & 30 & 46 & 32 & 12 \\
\hline$a$ & 0.00 & 0.00 & 0.00 & 0.00 & 0.00 & 0.00 & 0.08 & 0.00 & 0.00 & 0.04 & 0.06 & 0.00 \\
\hline$b$ & 1.00 & 1.00 & 1.00 & 1.00 & 1.00 & 1.00 & 0.92 & 1.00 & 1.00 & 0.96 & 0.94 & 1.00 \\
\hline Est-D & $n=19$ & 24 & 10 & 6 & 30 & 25 & 25 & 7 & 29 & 46 & 32 & 12 \\
\hline$a$ & 0.82 & 0.9 & 0.85 & 0.83 & 0.85 & 0.82 & 0.76 & 0.79 & 0.85 & 0.91 & 0.84 & 0.88 \\
\hline$b$ & 0.18 & 0.1 & 0.15 & 0.17 & 0.15 & 0.18 & 0.24 & 0.21 & 0.16 & 0.09 & 0.16 & 0.12 \\
\hline Es-B3 & $n=19$ & 24 & 11 & 6 & 30 & 26 & 25 & 7 & 29 & 45 & 32 & 12 \\
\hline$a$ & 0.87 & 0.85 & 0.91 & 0.75 & 0.83 & 0.65 & 0.66 & 0.43 & 0.90 & 0.73 & 0.67 & 0.87 \\
\hline$b$ & 0.13 & 0.15 & 0.09 & 0.25 & 0.17 & ${ }^{\circ} 0.33$ & 0.34 & 0.57 & 0.10 & 0.27 & 0.33 & 0.13 \\
\hline$c$ & 0.00 & 0.00 & 0.00 & 0.00 & 0.00 & 0.002 & 0.00 & 0.00 & 0.00 & 0.00 & 0.00 & 0.00 \\
\hline Acy-1 & $n=19$ & 28 & 11 & 6 & 30 & 26 & 25 & 7 & 29 & 46 & 32 & 12 \\
\hline$a$ & 0.97 & 1.00 & 1.00 & 1.00 & 0.97 & 0.98 & 0.98 & 0.93 & 0.98 & 0.96 & 0.89 & 0.96 \\
\hline$b$ & 0.03 & 0.00 & 0.00 & 0.00 & 0.03 & 0.02 & 0.02 & 0.07 & 0.02 & 0.04 & 0.11 & 0.04 \\
\hline Pep-2 & $n=19$ & 24 & 11 & 6 & 30 & 26 & 25 & 7 & 29 & 46 & 32 & 12 \\
\hline$a$ & 0.11 & 0.12 & 0.05 & 0.17 & 0.22 & 0.02 & 0.10 & 0.07 & 0.10 & 0.08 & 0.06 & 0.21 \\
\hline$b$ & 0.89 & 0.83 & 0.95 & 0.83 & 0.78 & 0.98 & 0.90 & 0.93 & 0.90 & 0.91 & 0.94 & 0.73 \\
\hline$c$ & 0.00 & 0.00 & 0.00 & 0.00 & 0.00 & 0.00 & 0.00 & 0.00 & 0.00 & 0.01 & 0.00 & 0.00 \\
\hline Amy-2 & $n=18$ & 24 & 11 & 6 & 30 & 24 & 25 & 7 & 30 & 44 & 26 & 10 \\
\hline$b$ & 0.972 & 0.958 & 1.00 & 0.917 & 0.933 & 0.896 & 0.980 & 0.857 & 0.833 & 0.85 & 0.67 & 0.65 \\
\hline$c$ & 0.028 & 0.042 & 0.00 & 0.083 & 0.067 & 0.104 & 0.020 & 0.143 & 0.167 & 0.15 & 0.33 & 0.35 \\
\hline Amy-3 & $n=19$ & 25 & 11 & 6 & 30 & 25 & 25 & 7 & 30 & 44 & 26 & 10 \\
\hline$a$ & 1.00 & 0.980 & 1.00 & 1.00 & 1.00 & 1.00 & 1.00 & 1.00 & 1.00 & 1.00 & 1.00 & 1.00 \\
\hline$b$ & 0.00 & 0.020 & 0.00 & 0.00 & 0.00 & 0.00 & 0.00 & 0.00 & 0.00 & 0.00 & 0.00 & 0.00 \\
\hline Pgm-2 & $n=19$ & 24 & 11 & 6 & 30 & 26 & 25 & 7 & 27 & 46 & 32 & 12 \\
\hline$a$ & 0.00 & 0.00 & 0.00 & 0.00 & 0.00 & 0.02 & 0.00 & 0.00 & 0.02 & 0.01 & 0.00 & 0.00 \\
\hline$b$ & 0.92 & 0.93 & 0.91 & 1.00 & 0.85 & 0.96 & 0.88 & 1.00 & 0.83 & 0.98 & 0.86 & 0.96 \\
\hline$c$ & 0.08 & 0.07 & 0.09 & 0.00 & 0.15 & 0.02 & 0.12 & 0.00 & 0.15 & 0.01 & 0.14 & 0.04 \\
\hline Pgm-3 & $n=19$ & 23 & 11 & 6 & 30 & 25 & 25 & 7 & 28 & 46 & 30 & 12 \\
\hline$b$ & 0.18 & 0.22 & 0.09 & 0.33 & 0.20 & 0.18 & 0.08 & 0.14 & 0.23 & 0.11 & 0.08 & 0.08 \\
\hline$c$ & 0.16 & 0.26 & 0.18 & 0.33 & 0.22 & 0.16 & 0.14 & 0.21 & 0.14 & 0.30 & 0.10 & 0.17 \\
\hline$d$ & 0.24 & 0.24 & 0.41 & 0.17 & 0.15 & 0.40 & 0.30 & 0.29 & 0.29 & 0.24 & 0.33 & 0.21 \\
\hline$e$ & 0.42 & 0.26 & 0.32 & 0.17 & 0.43 & 0.26 & 0.48 & 0.36 & 0.32 & 0.35 & 0.49 & 0.54 \\
\hline$f$ & 0.00 & 0.02 & 0.00 & 0.00 & 0.00 & 0.00 & 0.00 & 0.00 & 0.02 & 0.00 & 0.00 & 0.00 \\
\hline Dia & $n=19$ & 24 & 11 & 6 & $3 n$ & 26 & 25 & 7 & 28 & 45 & 32 & 12 \\
\hline$a$ & 0.00 & 0.00 & 0.00 & 0.00 & 0.00 & 0.00 & 0.00 & 0.00 & 0.00 & 0.01 & 0.00 & 0.00 \\
\hline$b$ & 0.579 & 0.604 & 0.636 & 0.667 & 0.733 & 0.423 & 0.760 & 0.571 & 0.500 & 0.61 & 0.61 & 0.50 \\
\hline$c$ & 0.421 & 0.396 & 0.364 & 0.333 & 0.267 & 0.577 & 0.240 & 0.429 & 0.500 & 0.38 & 0.39 & 0.50 \\
\hline
\end{tabular}

